\title{
Twin Reversed Arterial Perfusion (TRAP) Sequence: A Case Report in Fallujah Maternity and Children Hospital, Fallujah, Iraq
}

\author{
Samira T. Abdulghani Alaani \\ Central Committee of Birth defects registration and follow up, Fallujah Maternity and Children Hospital, Fallujah, Iraq
}

Email address:

samiraalaani@hotmail.com

To cite this article:

Samira T. Abdulghani Alaani. Twin Reversed Arterial Perfusion (TRAP) Sequence: A Case Report in Fallujah Maternity and Children Hospital, Fallujah, Iraq. Clinical Medicine Research. Vol. 4, No. 5, 2015, pp. 151-153. doi: 10.11648/j.cmr.20150405.15

\begin{abstract}
Introduction. Twin reversed arterial perfusion (TRAP) sequence is a rare complication of multiple pregnancy caused by defects in early embryogenesis. The pump twin supplies the acardiac recipient twin with blood, and although the pump twin is usually structurally normal, congenital anomalies have sometimes been reported. We report a case of twin reversed arterial perfusion sequence with feet polydactly in the surviving pump twin. This was the $1^{\text {st }}$ case reported in Fallujah city, Iraq. Case report. A 22 years old. gravida 2, para 0. abortion 1, full term lady presented to the delivery room with labour pain with no history of any prenatal care. She gave no history of any familial congenital anomaly and there was no history of consanguinity with her hasbund. She has been referred for cesearian section delivery as an emergency as there was no progress in labour. Ultrasound examination at the delivery room revealed the diagnosis of monozygotic twin, one was normal $\&$ the $2^{\text {nd }}$ was diagnosed as (abnormal) with difficulty in visualization of the fetal parts and gender. Conclusion. Twin-Reversed Arterial Perfusion (TRAP) sequence is a rare complication of monozygotic multiple gestation. Accurate antenatal diagnosis is essential to improve the prognosis of this rare entity.
\end{abstract}

Keywords: TRAP Sequence, Twin Pregnancy, Polydactly, Fallujah

\section{Introduction}

Twin reversed arterial perfusion (TRAP) sequence is a rare complication of monozygotic multiple pregnancy. The presence of an acardiac twin occurs in one of every 35,000 twin pregnancies and in $1 \%$ of monochorionic twin pregnancies ${ }^{1}$. In cases of TRAP, the mortality rate for the normal (pump) twin is reported to be approximately $50 \%{ }^{2}$. The majority of pump twins are congenitally normal, but anomalies are sometimes observed, including cardiogenic defects, gastroschisis and skeletal abnormalities ${ }^{3}$.

Polydactly is a condition in which a person has more than five fingers per hand or five toes per foot. This trait involves only one gene that can cause several variations. In most cases, this is not caused by a genetic disease ${ }^{4}$.

We hereby report acase of monochorionic twin pregnancy. the $1^{\text {st }}$ twin born with feet polydactly. the $2^{\text {nd }}$ was acase of twin reversed arterial perfusion sequence.

\section{Case Report}

On 17-7-2013. a 22 years old. gravida 2, para 0 . abortion 1 , full term lady presented to the delivery room in Fallujah maternity and children hospital with labour pain with no history of any prenatal care. she is from rural area in Fallujah. She gave no history of any familial congenital anomaly and there was no history of consanguinity with her hasbund. She was not hypertensive or diabetic, non smoker, non alcoholic and has no history of using any teratogenic drugs or exposure to any irradiation. She has ahistory of 8 weeks miscarriage few months before her last pregnancy. Ultrasound examination at the delivery room, less than 30 minutes before delivery revealed the diagnosis of monozygotic twin. one was normal $\&$ the $2^{\text {nd }}$ was diagnosed as ( abnormal ) with difficulty in visualization of the fetal parts and gender. She has been referred for cesearian section delivery as an emergency at about $9 \mathrm{pm}$ as there was no progress in labour. At delivery. The $1^{\text {st }}$ twin was female, 2500 gm body weight born with polydactly ( an extra toe ) of both feet with no other anomaly in other parts of her body. She have been discharged home 
about 10 hours after delivery on her family's responsibility. the $2^{\text {nd }}$ twin was grossly abnormal with no differentiation of the body parts. it looked like amass weighing $1500 \mathrm{gm}$. which was divided in to 2 parts. one small rounded representing the head with no eyes \&nose with small skin tags on both sides representing the ears and one larger elongated part representing the rest of the body with no clear defferentiation of chest, abdomen, pelvis or genitalia and no limbs (Fig 1 \& 2 ). on auscultation there was asound of beating vanished in less than 10 minutes after birth and it may represent placental circulation.

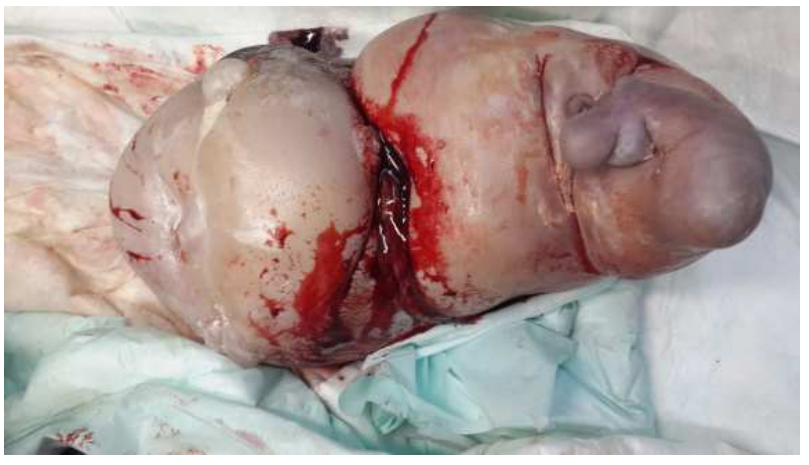

Figure 1. TRAP sequence (anterior view).

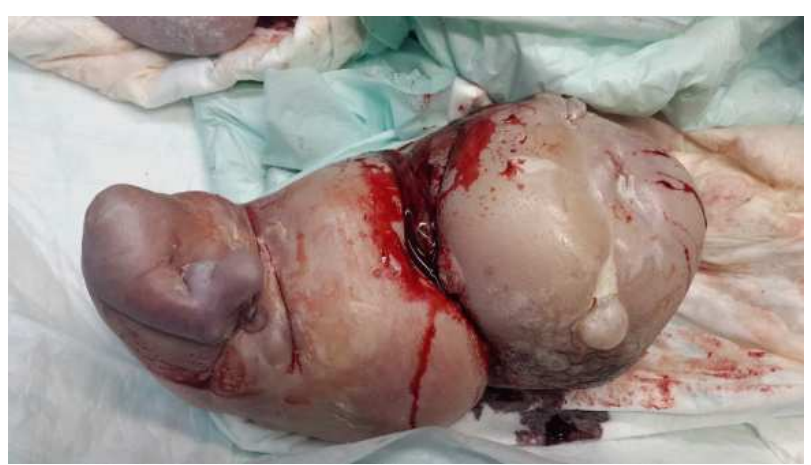

Figure 2. TRAP sequence (lateral view).

\section{Discussion}

Fallujah is a city in the Iraqi province of Al Anbar. located roughly 69 kilometers west of Baghdad on the Euphrates with about 600,000 population.

Anectodal reports indicated increasing incidence of birth defects in the years following US attacks in 2004 which proved to be due to irradiation ${ }^{5,6,7,8}$. The health system. although it showed some improvement in the last 2 years. is still underdeveloped and the security situation in the city is still bad. many cases of birth defects are still underdiagnosed or not documented because of that. This was the $1^{\text {st }}$ documented case of TRAP sequence in Fallujah Maternity and Children Hospital. but there are many cases of polydactly. most are not familial and appear for the $1^{\text {st }}$ time.

TRAP sequence is a rare complication of monochorionic multiple pregnancy. It is classified according to the degree of cephalic and truncal maldevelopment. The first type is acardiac acephalus, where no cephalic structures present. The second is acardius-anceps where some cranial structure and or neural tissue present. for which our case may belong. The third is acardius-acormus with cephalic structure but no truncal structures present. The fourth type is acardius amorphus with no distinguishable cephalic or truncal structure ${ }^{9 .}$ The first cases of acardia were reported by Benedetti in 1533 and Benedictus in 1539, and later by Geoffroy in $1836^{10}$.

Several theories had been postulated to explain TRAP sequence. The most accepted theory is that artery-to-artery anastomosis between the monochorionic twins in the first trimester is the fundamental event in development TRAP sequence $^{11}$. This abnormal circulation may result in early tissue hypoxia with resultant disruption of development of the cardiovascular system and a cascade of disruption of organ development in the recipient twin. Because the blood first perfuse the lower segment of the anomalous twin, the lower limbs and scrotum receive comparatively more oxygen than the upper segment of the body ${ }^{11,12}$

The anomaly is fatal for the recipient twin. The pump twin may develop heart failure because of an increased cardiac demand. Numerous obstetric complications are associated with TRAP syndrome such as hydrops fetalis, polyhydramnios, umbilical cord accidents, preterm delivery or fetal death of the pump twin. The prominent features of the recipient twin are: total or partial absence of cranial vault,holoprosencephaly, absent facial structures, anophthalmia, microphthalmia, cleft lip, cleft palate, absent or rudimentary limbs, diaphragmatic defects, absent lungs and heart, esophageal atresia, ventral wall defects, ascites, absent liver and gallbladder, edema of the skin and single umbilical artery ${ }^{13,14}$.

Risk for cardiac insufficiency in the pump twin increases proportionally to the relative increase in weight of recipient-to pump twin. Risk for congestive heart failure increases to $94 \%$ as the acardiac twin achieves a size more than half the size of the pump twin ${ }^{15}$. At this juncture, some form of minimally invasive intervention is warranted to occlude vascular supply to the acardiac twin through cord occlusion techniques or intrafetal ablation $^{16}$. Cord occlusion has been attempted by embolization, cord ligation, laser coagulation, bipolar diathermy, and monopolar diathermy, while intrafetal ablation has been performed with alcohol, monopolar diathermy, alcohol, monopolar diathermy, interstitial laser, and radiofrequency. with radiofrequency ablation, greater than $90 \%$ survival can be achieved in monochorionic diamniotic pregnancies complicated by TRAP sequence.

An exact preoperative evaluation of the vascular flow including Doppler sonography is however mandatory ${ }^{17}$.

\section{Consent}

Consent for publication from both parents have been obtained

\section{Conclusion}

Twin-Reversed Arterial Perfusion (TRAP) sequence is a rare complication of monozygotic multiple gestation. 
Accurate antenatal diagnosis is essential to improve the prognosis of this rare entity. Important steps should be taken to raise the awareness about the importance af antenatal visits and care in our population to help early diagnosis of congenital anomalies. Though many patients can benefit from conservative treatment, minimally invasive antenatal treatment modalities for the vascular anastomosis improve the outcome of the pump twin.

\section{Acknowledgment}

I would like to extend my thanks and appreciation to Islah reparations represented by Miss Kali Rubaii for covering the publications charges of this paper, and also to Dr. Muntaha Hashim Al-Alwany (fetal medicine specialist in Fallujah maternity and children hospital) for her assistance in the diagnosis of this very rare anomaly.

\section{References}

[1] Healey M: Acardia: predictive risk factors for the co-twin's survival. Teratology 1994, 50:205-213.

[2] Gembruch U, Viski S, Bagamery K, Berg C, Germer U: Twin reversed arterial perfusion sequence in twin-to-twin transfusion syndrome after the death of the donor co-twin in the second trimester. Ultrasound Obstet Gynecol 2001, 17: 153-156.

[3] Chen CY, Wu YC, Chen CL, Yang ML: Acardiac syndrome coexisting with complex skeletal dysplasia in the co-twin: $3 \mathrm{D}$ sonographic findings. J Clin Ultrasound 2007, 35:387-389.

[4] www.nlm.nih.gov/.../003176. United States National Library of Medicine.

[5] Alaani S, Al-Fallouji M, Busby C, Hamdan M: Pilot Study of Congenital Anomaly Rates at Birth in Fallujah, Iraq, 2010. JIMA: Vol 44, 2012. http://dx.doi.org/10.5915/44-1-10463.

[6] Busby C, Hamdan M, Ariabi E. Cancer, infant mortality and birth sex-ratio in Fallujah, Iraq 2005-2009. Int J Environ Res Public Health. 2010;7:2828-37. http://doi.org/ck8j8z.

[7] Alaani S, Savabieasfahani M, Tafash M et al. Four polygamous families with congenital birth defects from Fallujah Iraq. Int $\mathbf{J}$ Environ Res Public Health. 2011; 8: 89-96. http://dx.doi.org/10.3390/ijerph8010089

[8] Alaani S, Tafash M, Busby C, et al. Uranium and other contaminants in hair from the parents of children with congenital anomalies in Fallujah, Iraq. Confl Health. 2011; 5: 15. http://dx.doi.org/10.1186/1752-1505-5-15.

[9] Mohanty C, Mishra OP, Singh CP, et al. Acardiac Anomaly Spectrum. Tetralogy 2000; 62: 356-9.

[10] Shashidhar B. B N kishore kumar. R.Sheela. R.Kalyani. N. Anithae, Prem Sai Reddy. Twin reversed arterial perfusion (TRAP) Sequence: (Acardius Amorphous) a case report and review of literature. Int J Biol Med Res. 2012; 3(1): 1453-1455.

[11] Gembruch U, Viski S, Bagamery K, et al. Twin Reversed Arterial Perfusion Sequence in Twin- to-Twin Transfusion Syndrome after the Death of the Donor Co-Twin in the Second Trimester. Ultrasound Obstet Gynecol 2001; 17: 153-6.

[12] Luiz N. TRAP Syndrome. Indian Pediatr 2003; 40: 683-4.

[13] Weisz B, Peltz R, Chayen B, et al. Tailored Management of Twin Reversed Arterial Perfusion (TRAP) Sequence. Ultrasound Obstet Gynecol 2004; 23: 451-5.

[14] Gibson JY, D'Cruz CA, Patel RB, et al. Acardiac Anomaly: Review of the Subject with Case Report and Emphasis on Practical Sonography. J Clin Ultrasound 1986; 14: 541-5.

[15] Izquierdo L, Smith J, Gilson G, et al. Twin, Acardiac, Acephalus. Fetus 1991; 1: 1-3.

[16] Tan TYT, Sepulveda W. Acardiac twin: A systematic review of minimally invasive treatment modalities Ultrasound Obstet Gynecol. 2003; 22: 409-419.

[17] Ishimatsu J, Nakanami H, Hamada T, Yakushiji M. Color and pulsed Doppler ultrasonography of reversed umbilical blood flow in an acardiactwin. Asia Oceania J Obstet Gynaecol. 1993; 19: $271-275$. 